\title{
Analysis Of Lpg Cylinder Using Composite Materials
}

\author{
T.Ashok, A. Harikrishna \\ M. Tech Student K.S.R.M College of Engineering Kadapa Andhra Pradesh, India \\ Assistant Professor in Mechanical Engineering K.S.R.M College of Engineering Kadapa Andhra Pradesh, India
}

\begin{abstract}
This paper aims is innovation of alternative materials of Liquid petroleum gas (LPG). So, the finite element analysis of Liquefied Petroleum Gas (LPG) cylinders made of Steel and Fiber Reinforced Plastic (FRP) composites has been carried out. Finite element analysis of composite cylinder subjected to internal pressure is performed. Layered shell element of a versatile FE analysis package ANSYS (version 11.0) has been used to model the shell with FRP composites.

A number of cases are considered to study the stresses and deformations due to pressure loading inside the cylinder. First, the results of stresses and deformation for steel cylinders are compared with the analytical solution available in literature in order to validate the model and the software. The weight savings are also presented for steel, Glass Fiber Reinforced Plastic (GFRP) composites LPG cylinders. Variations of stresses and deformations throughout the cylinder made of steel and GFRP are studied.
\end{abstract}

\subsection{Liquefied Petroleum Gas (LPG)}

\section{Introduction}

LPG (propane or butane) is a colour less liquid which readily evaporates into a gas. It has no smell, although it will normally have an odour added to help detect leaks. When mixed with air, the gas can burn or explode when it meets a source of ignition. It is heavier than air, so it tends to sink towards the ground. LPG is composed predominantly a mixture of the following hydrocarbons: propane, propylene, butane or butylenes. LPG is stored and handled as a liquid when under pressure inside a LP-Gas container. When compressed moderately at normal temperature, it becomes liquid. When gas is withdrawn, the pressure drops and the liquid reverts to gas. This means that it can be transported and stored as liquid and burnt as gas. The expansion ratio of gas liquid is 270:1 at atmospheric pressure. It is expansion factor which makes LP-Gas more economical to transport and store large quantities of gaseous fuel in a small container .Containers are normally filled $80-85 \%$ liquid, leaving $15-20 \%$ vapour space for expansion due to temperature increase.The vapour pressure of propane increases as the liquid temperature increases. Propane at $-42^{\circ} \mathrm{C}$ inside a container would register zero pressure. At $0^{\circ} \mathrm{C}$, propane vapour pressure will increase to $380 \mathrm{k}$ pa. At $38^{\circ} \mathrm{C}$, the vapour pressure of propane would be $1200 \mathrm{k} \mathrm{pa}$.

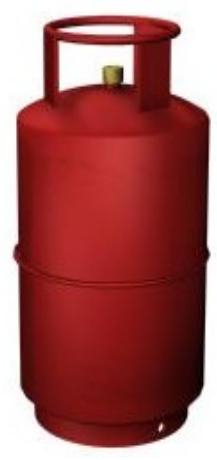

Fig.1.1:Conventional Steel LPG cylinder

\subsection{Composite Materials}

\section{Composite Materials}

A composite material is formed by combining two or more materials to achieve some superior properties. In other words, composite materials are macroscopic combinations of two or more distinct materials having a discrete and recognizable interface separating them. Thus composites are heterogeneous materials. By combining two or more materials together, we can tailor make composite materials, which are lighter and stiffer, stronger that any other materials man have ever used. A variety of materials, which we see around us, are composites e.g. wood, bones etc. 


\subsection{Fiber Reinforced composite}

Fiber Reinforced composite materials consists of fibers of high strength and modulus embedded in or bonded to matrix with distinct interfaces between them. In this form, both fibers and matrix retain their physical and chemical identities, yet they produce a combination of properties that cannot be achieved with either of the constituents acting alone. In general, fibers are the principal load carrying members, while the surrounding matrix keeps them in the desired location and orientation, acts as a load transfer medium between them, and protects them from environment damages due to elevated temperatures and humidity for example. Thus, even though the fibers provide reinforcement for the matrix, the latter also serves number of useful functions in a fiber reinforced composite material.

\subsubsection{Fibers}

Fibers are the dominant constituent of most composite systems, and one of the main objectives of any design should be to place the fibers in positions and orientations so that they are able to contribute efficiently to load-carrying capability. The most widely available fiber form for advanced structural applications is continuous tows. These produce highly anisotropic materials of very high stiffness and strength in the direction of the reinforcement. Fibers can be of the same material within a lamina or several fibers mixed (hybrid).

\subsubsection{Matrices}

The purpose of the composite matrix is to bind the fibers together by virtue of its cohesive and adhesive characteristics, to transfer load to and between fibers, and to protect them from environment and handling. In addition to these, the matrix keeps the reinforcing fibers in the proper orientation and position so that they can carry the intended loads, distributes the loads more or less evenly among the fibers, provides resistance to crack propagation and damage, and provides all the interlaminar shear strength of the composites. Furthermore, the matrix generally determines the overall service temperature limitations of the composite, and may also control its environmental resistance.

\subsubsection{Basic building blocks in fiber reinforced composites}

Manufacturing of composite structure starts with the incorporation of a large number of fibers into a thin layer of matrix to form a lamina(ply). If continuous fibers are used in making the lamina, they may be arranged either in a uni-directional orientation or in a bi-directional orientation . For a lamina containing unidirectional orientation, the composite material has the highest strength and modulus in the longitudinal direction of the fibers. However in the transverse direction its strength and modulus is very low. For a lamina containing bi-directional orientational fibers, the strength and modulus can be varied by employing different amounts as well as different types of fibers in the longitudinal and transverse directions . For a balanced lamina, these properties are the same in both directions

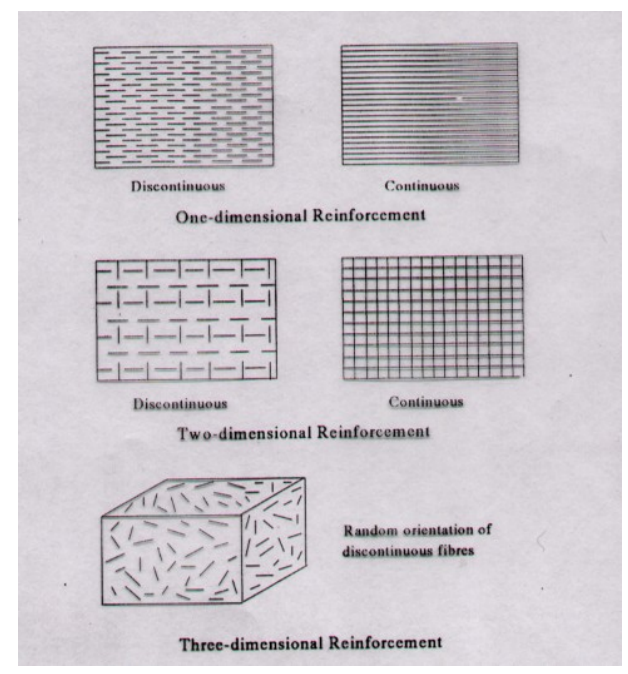

Fig: 2.1 Some possible ways to orient fibers in FRP composites

A lamina can also be constructed using discontinuous fibers in a matrix. The fibers can be arranged either in a unidirectional orientation or in a random orientation. Discontinuous fiber reinforced composites have lower strength and modulus than continuous fiber composites. However with random orientation of fibers, it is possible to obtain nearly equal mechanical and physical properties in all directions in the plane of the 
lamina. The thickness required to support a given load or maintain given deflection in a fiber reinforced composite structure is obtained by stacking several laminas in a specified sequence to form a laminate. Various laminas in a laminate may contain fibers in one direction or in different directions .

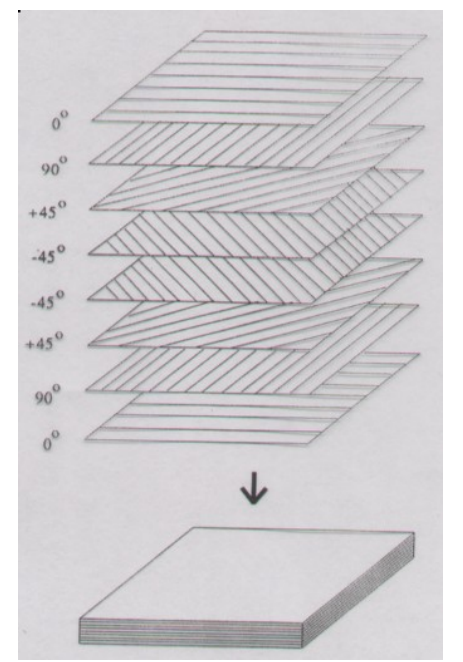

Fig.2.2: A Typical Lamina Constitution and fiber orientations

\subsection{Classification of fibers}

The common commercially available fibers include the following:

$\diamond \quad$ Glass fibers

$\diamond \quad$ Carbon Graphite fibers

$\diamond \quad$ Aramid fibers

$\diamond \quad$ Boron fibers

$\diamond \quad$ Polyethylene fibers

$\diamond \quad$ Other inorganic fibers.

In this thesis we are using glass and carbon fibers.

\subsubsection{Glass fibers}

Glass fibers are the most common of all reinforcing fibers for polymeric matrix composites. The principal advantages of glass fibers are low cost, high tensile strength, high chemical resistance and excellent insulating properties. The disadvantages are low tensile modulus, relatively high specific gravity, sensitivity to abrasion, with handling, which frequently decreases its tensile strength, relatively low fatigue resistance and high hardness, which causes excessive wear on molding dies and cutting tools. The two types of glass fibers commonly used in the fiber reinforced plastics industry are E-glass and S- glass . In this project we are using Sglass fibers. The Table 1.1 shows the composition of $\mathrm{E}$ and $\mathrm{S}$ glass fibers.

Table 2.1:Typical composition of Glass Fibers

\begin{tabular}{|l|l|l|l|l|l|l|}
\hline $\begin{array}{l}\text { Typical composition of } \\
\text { Glass Fibers }\end{array}$ & SIO2 & AL2O3 & CAO & MGO & B2O3 & NA2O \\
\hline E Glass & 54.5 & 14.5 & 17 & 4.5 & 8.5 & 0.5 \\
\hline S Glass & 64 & 26 & & 10 & & \\
\hline
\end{tabular}

\subsection{Advantages and Disadvantages of composites}

\subsubsection{Advantages:}

$\diamond \quad$ Weight reduction High strength or stiffness to weight ratio.

$\diamond \quad$ Tailor able properties. Can tailor strength or stiffness to be in the load direction.

$\diamond \quad$ Redundant load paths (fiber to fiber).

$\diamond \quad$ Higher fatigue endurance limit (upto $60 \%$ of UTS)

$\diamond \quad$ Inherent damping and high corrosion resistance.

$\diamond \quad$ Improved torsional stiffness and impact resistance properties

$\diamond \quad$ Better dimensional stability over temperature fluctuation Low coefficient of thermal expansion.

$\diamond$ Appropriate inhibitors/additives can impart very good fire retardance properties in composites.

$\diamond \quad$ Lower manufacturing costs because of less part count.

$\diamond \quad$ Easy of manufacturing and fabrication. Molding to any shape with polymer composites. 


\subsubsection{Disadvantages:}

$\diamond \quad$ High cost of raw materials and fabrication.

$\diamond \quad$ Transverse properties may be weak.

$\diamond \quad$ Matrix is weak, low toughness.

$\diamond \quad$ Reuse and disposal may be difficult.

$\diamond \quad$ Analysis is difficult.

\subsection{Applications of composites}

The figure shows Worldwide application of composites in year 2000

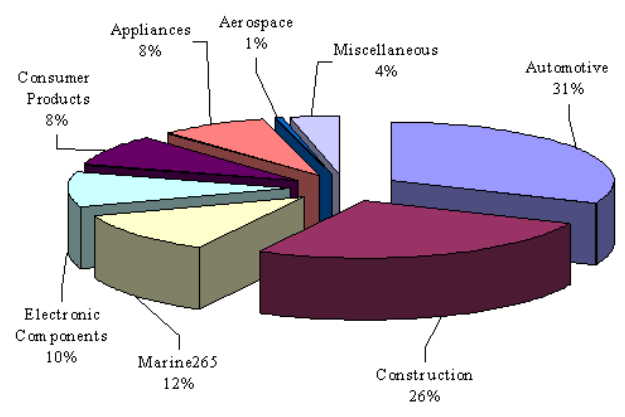

\section{About Fem}

The Finite Element Method (FEM) has become a powerful tool for the numerical solution of a wide range of engineering problems. Applications range from deformation and stress analysis to automotive, aircraft, spacecraft, missile, building, and bridge structures to field analysis of heat flux, fluid flow, magnetic flux, seepage, and other flow problems. With the advances in computer technology and CAD systems, complex problems can be modeled with relative ease. Several alternative configurations can be tried out on a computer before the first prototype is built. All of this suggests that we need to keep pace with these developments by understanding the basic theory, modeling techniques, and computational aspects of finite element method. Today, the development in mainframe computers and availability of powerful microcomputers has brought this method within reach of students, engineers, and scientists in research organizations. In this method of analysis, a complex region defining a continuum is discretized into simple geometric shapes called finite elements. The material properties and the governing relationships are considered over these elements and expressed in terms of unknown values at element corners. An assembly process (known as globalization), duly considering the loading and constraints, results in a set of equations. Solution of these equations gives us the approximate behavior of the continuum.

Finite element analysis involves three stages of activity: Preprocessing, Processing, and Post processing. Preprocessing involves the preparation of data, such as nodal coordinates, connectivity, mesh generation, boundary conditions, and loading and material informations. The processing stage involves stiffness generation, stiffness modification, and solution of equations, resulting in the evaluation of nodal variables. Other derived quantities, such as gradients or stresses, may be evaluated at this stage. In this stage the datas are prepared in a formatted input file. The post processing stage deals with the presentation of results. Typically, the deformed configuration, mesh plotting, temperature and stress distribution are computed and displayed at this stage. A complete finite element analysis is a logical interaction of the three stages.

The present analysis includes two element types. First is four-noded shell element for the isotropic materials like steel, and the second is eight-noded layered shell element for the orthotropic materials like composites.

\subsection{FE Analysis, Results and Discussions}

\subsubsection{LPG Cylinder wall thickness calculation} 3.1.2 LPG Cylinder made of steeel

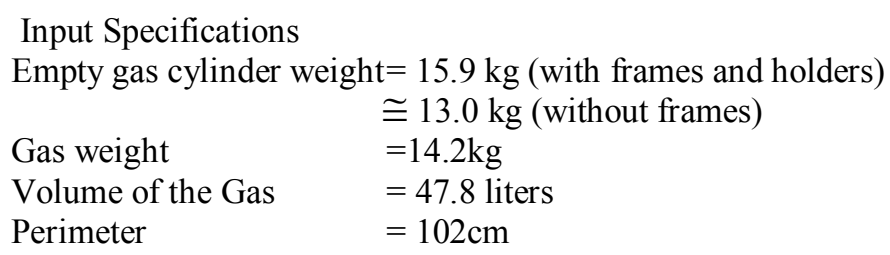


Assumptions: End dome is hemispherical

Cylinder has been modeled without end frames.

Thickness of the cylinder $=2.4 \mathrm{~mm} \sim 2.5 \mathrm{~mm}$

\subsubsection{Geometric Model}

The geometry of the gas cylinder is shown in fig. 5.1. It has been approximated by hemispherical ends of $160 \mathrm{~mm}$ radius. Length of the cylindrical portion is $360 \mathrm{~mm}$. The total length of the cylinder is $680 \mathrm{~mm}$

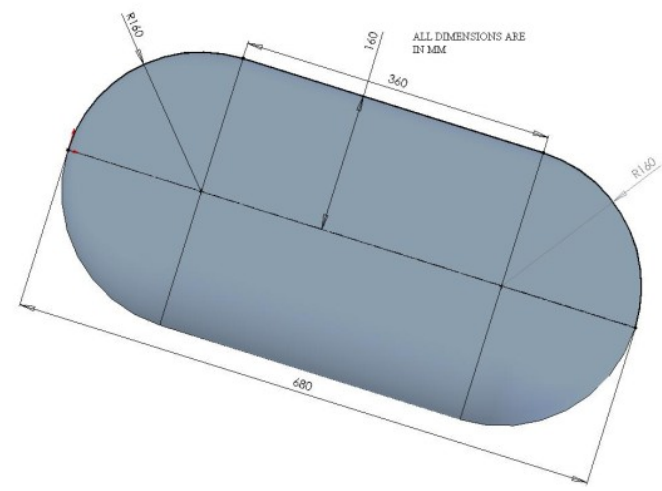

Fig 3.1 Geometric model of LPG cylinder without end frames

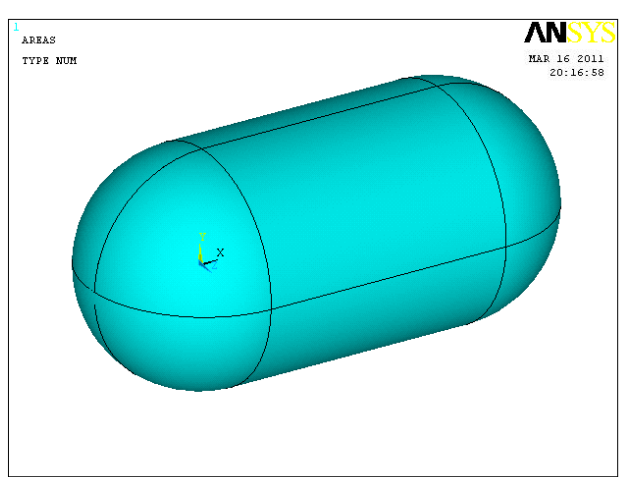

Fig 3.2: 3-D View of the geometric model

\subsubsection{Model Validation by Classical Approach}

First the FE model of the cylinder has been validated with classical close form solution method. The FE results are matching very closely with analytical solution given in 5.1.8.

The cylinder has been modeled in ANSYS 9.0. The four-noded shell element (SHELL63) with six degrees of freedom $\left(\mathrm{u}_{\mathrm{x}}, \mathrm{u}_{\mathrm{y}}, \mathrm{u}_{\mathrm{z}}\right.$, rotx, roty, rotz) has been used to discretize the cylinder.

\subsubsection{Brief discussion on element type Shell 63 :}

Shell 63 has both bending and membrane capabilities, both in-plane and normal loads are permitted.The element has six degrees of freedom at each node translations in the nodal $\mathrm{x}, \mathrm{y}$ and $\mathrm{z}$ directions and rotations about the nodal $\mathrm{x}, \mathrm{y}$ and $\mathrm{z}$ axes.Stress stiffening and large deflection capabilities are included.

\subsubsection{Input data:}

The geometry node locations and the coordinate system for this element are shown in figure 5.3. The element is defined by four nodes, four thicknesses, an elastic foundation stiffness, and the orthotropic material properties. Orthotropic material directions correspond to the element coordinate directions.

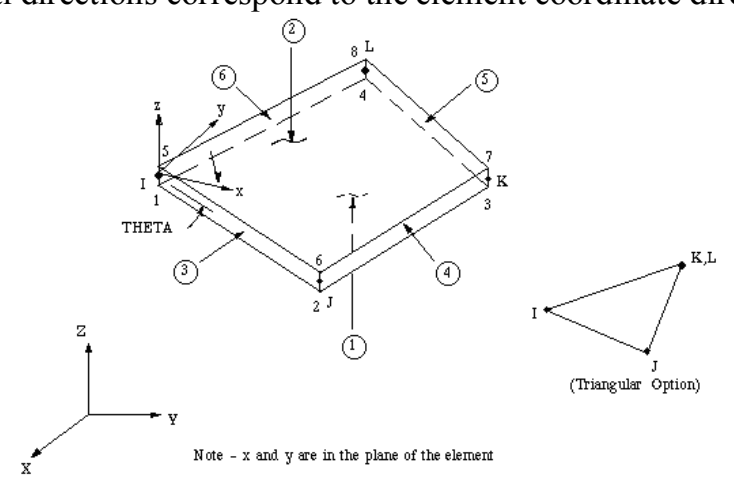

The element $\mathrm{x}$-axis may be rotated by an angle THETA(in degrees). The thickness is assumed to vary smoothly over the area of the element, with the thickness input at the four nodes. If the element has a constant thickness, only $\mathrm{TK}(1)$ need to be input. If the thickness is not constant, all four thicknesses must be input .

\subsubsection{Output:}

The solution output associated with the element is in two forms:

$\diamond$ nodal displacements included in the overall nodal solution and

$\diamond \quad$ additional element output. 


\subsubsection{Material Properties}

The material used is steel for which material properties are listed below.
Density, $\rho$
$=7.8 \mathrm{gm} / \mathrm{cc}$
Young's modulus, E
$=207 \mathrm{Gpa}$
Poisson ratio, $v$
$=0.3$
UTS, $\sigma$
$=800 \mathrm{MPa}$
Yield strength
$=480 \mathrm{MPa}$

\subsubsection{Loads and Boundary Conditions}

The figure 3.1 is the finite element model of the steel cylinder. Mapped mesh has been done for this model taking size control as $28 \times 4$ along the circumference of hemisphere and size control 40 along the longitudinal length of the cylinder.

An internal pressure load of 1.2 MPa has been applied as shown in fig.3.3. To simulate a proper boundary condition, the mid symmetrical nodes of the cylinder are fixed in X-degree of freedom $(\mathrm{Ux}=0)$ as shown in fig.3.2. Here it has been assumed that the mid plane deformation along $\mathrm{X}$-direction is zero.

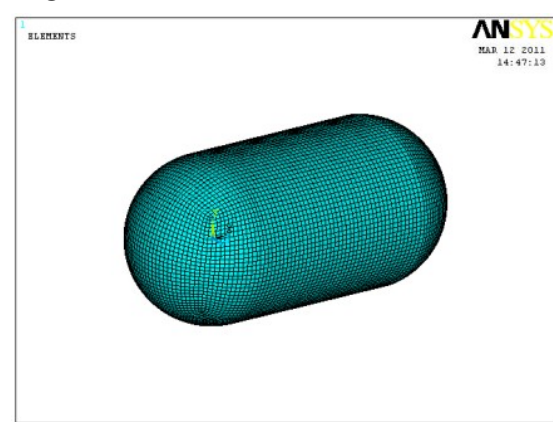

Fig 3.1: FE Mesh Model for Steel cylinder

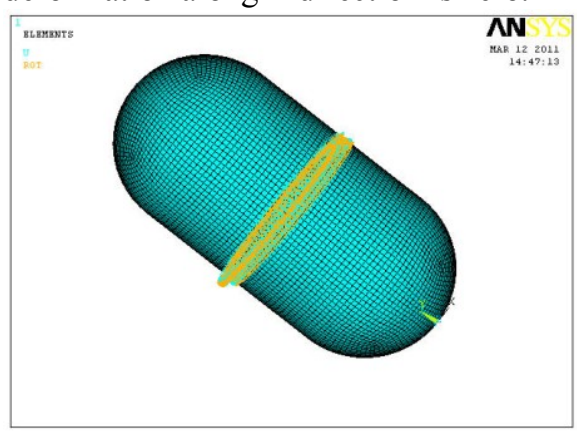

Fig 3.2 Boundary condition applied on cylinder

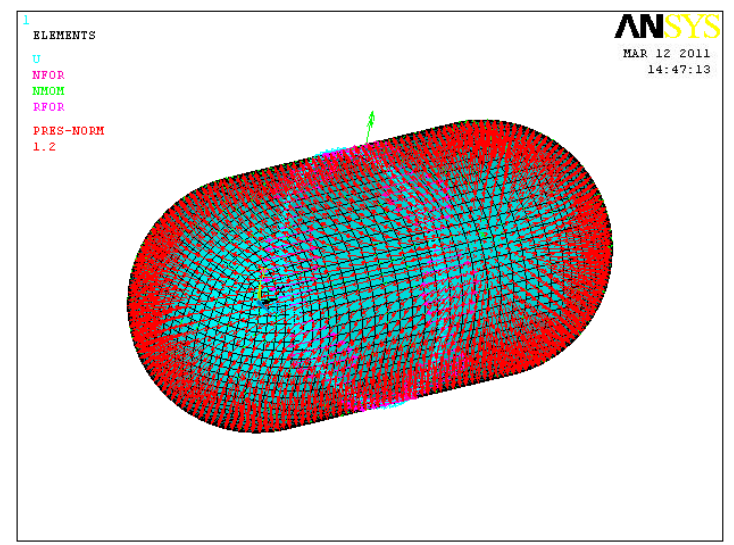

\subsection{Results and Discussions}

Fig 3.3 Internal pressure applied on Steel cylinder

The longitudinal (X-component) ) Displacement contour plot is shown in fig.3.4. For which the maximum displacement is occur at the extreme points in the $\mathrm{x}$-direction.. Maximum Longitudinal displacement $=0.030405 \mathrm{~mm}$.

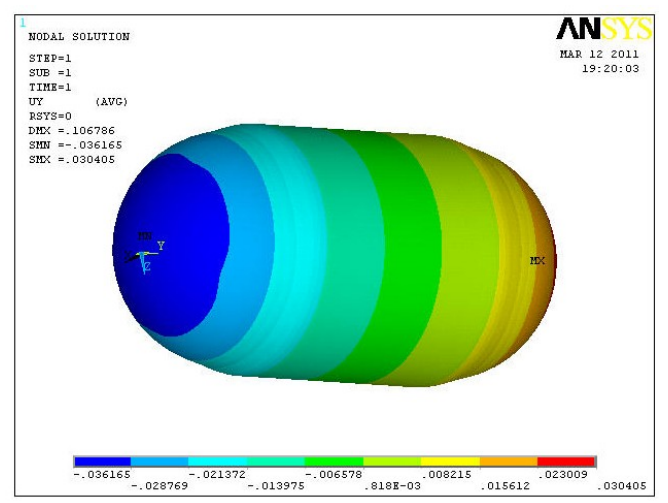

Fig 3.4 Longitudinal Displacement(in mm) plot steel cylinder

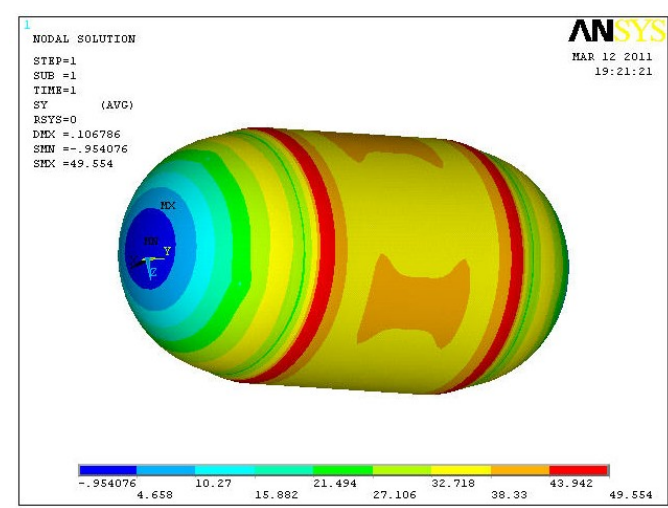

Fig 3.5 Longitudinal stress(in MPa) contour plot for for steel cylinder 
The Hoop (Y-component) ) Stress contour plot is shown in fig.3.6. Maximum Hoop stress $=78.928 \mathrm{MPa}$

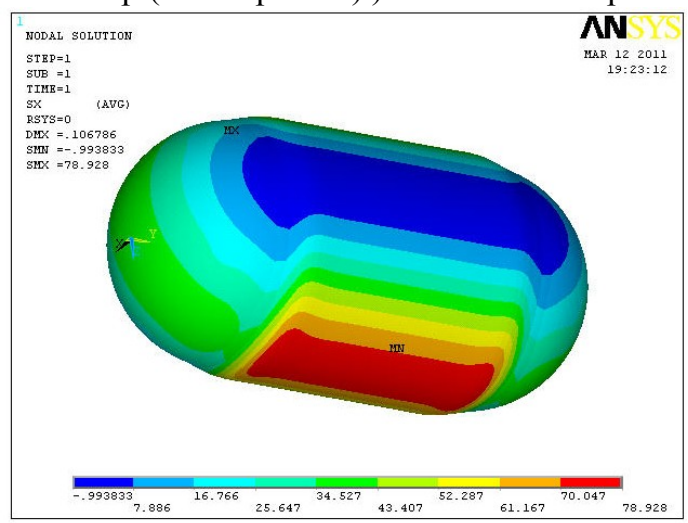

Fig 3.6 Hoop stress (M Pa) contour plot Steel cylinder

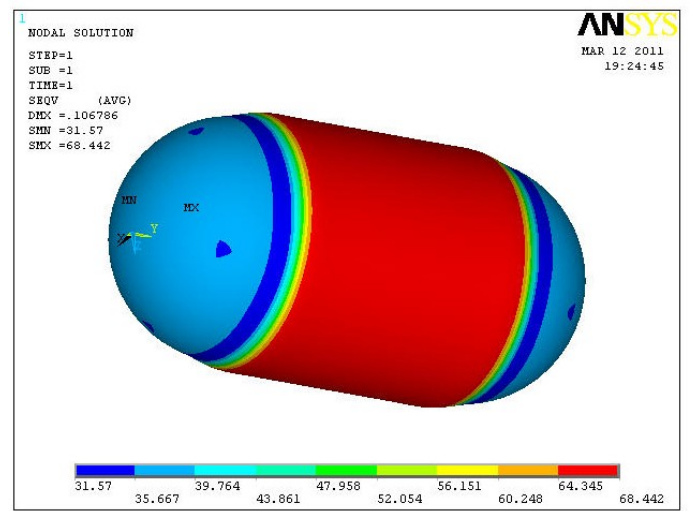

Fig 3.7Von-mises stress contour plot for steel cylinder

figure 3.7is the figure showing the Von mises stress plot for steel cylinder .For which the Maximum Von mises stress $=68.442 \mathrm{M} \mathrm{Pa}$ and the yield strength of the steel is $480 \mathrm{M} \mathrm{Pa}$. so, the maximum stress occurring is within the limits and the design is safe Maximum Von mises stress $=68.81 \mathrm{M} \mathrm{Pa}$

The figure 3.8 shows the nodes which are selected to draw the Longitudinal Displacement variation graph (fig 3.9) and the Longitunal Stress variation graph(fig 3.10) for Steel Cylinder.

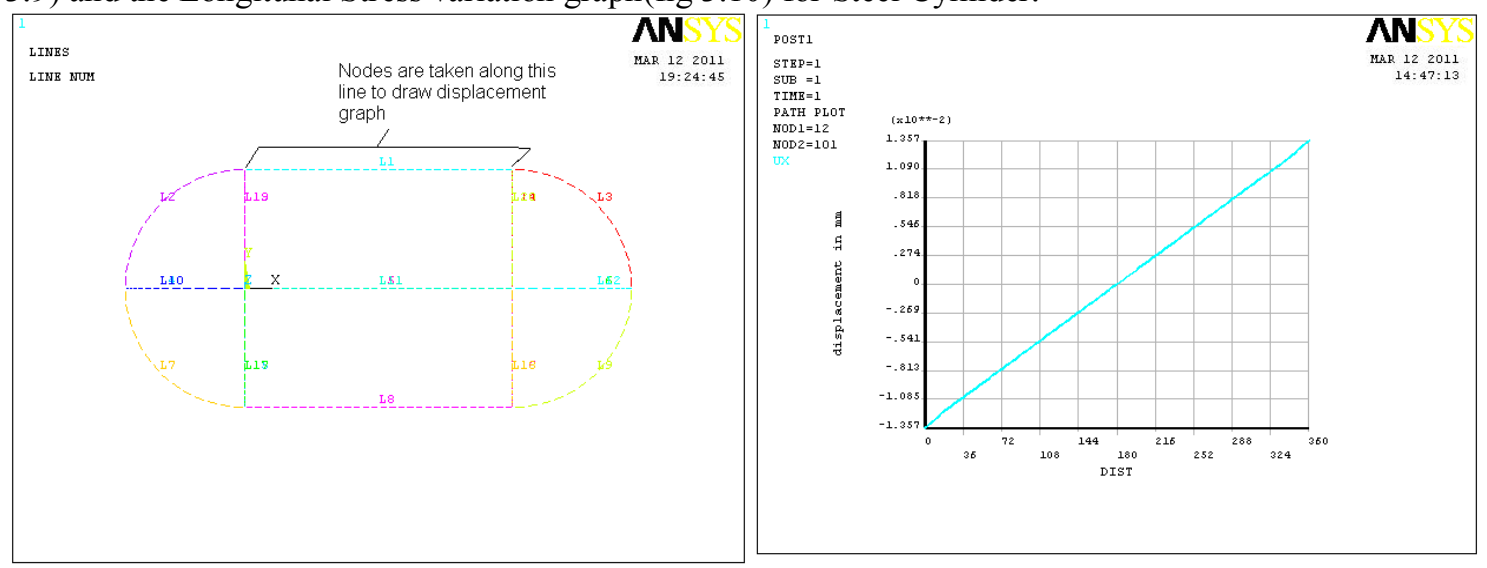

Fig 3.8: Nodes selected along the axis

Fig 3.9 : Graph for the Longitudinal Displacement

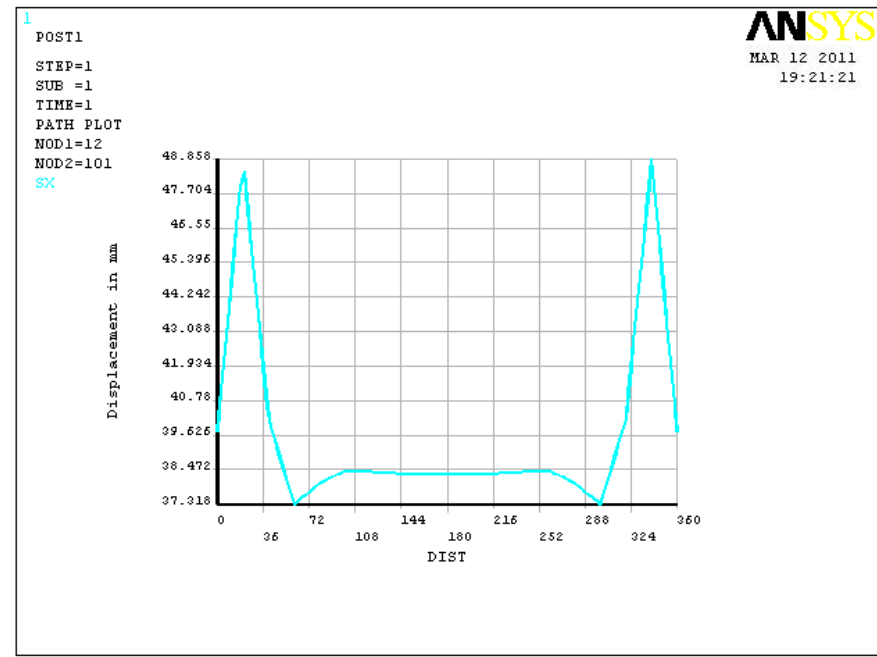

Fig:3.10 Longitunal Stress variation Graph for Steel Cylinder 


\subsubsection{Analytical Calculation for LPG Steel cylinder}

\subsubsection{Cylindrical portion}

Hoop stress,

$$
\sigma_{H}=\frac{P D}{2 t}=\frac{1.2 * 320}{2 * 2.5}
$$

Longitudinal stress,

$$
\sigma_{L}=\frac{P D}{4 t}=\frac{1.2 * 320}{4 * 2.5}
$$

Longitudinal strain,

$$
\varepsilon=\frac{\sigma_{L}}{E}=\frac{38.4}{207 * E 3}
$$

Longitudinal Deformation, $\delta=$

$=0.050 \mathrm{~mm}$.

\subsubsection{Hemispherical End dome portion}

$$
\text { Hoop stress, } \quad \sigma_{L}=\frac{P D}{4 t}=\frac{1.2 * 320}{4 * 2.5}=38.4 \mathrm{M} \mathrm{Pa}
$$

Table 3.5 Comparison of Results of steel

\begin{tabular}{|l|l|c|c|}
\hline Sl. No. & \multicolumn{1}{|c|}{ RESULTS } & FE METHOD & ANALYTICAL METHOD \\
\hline 1 & Longitudinal stress, M Pa & 43.48 & 38.4 \\
\hline 2 & Hoop stress, M Pa & 79.30 & 76.8 \\
\hline 3 & Von-mises stress, M Pa & 68.81 & 66.5 \\
\hline 4 & Longitudinal Deformation, $\mathrm{mm}$ & 0.033 & 0.050 \\
\hline
\end{tabular}

\subsection{Loads and Boundary Conditions}

To simulate a proper boundary condition, the mid symmetrical nodes of the cylinder are fixed in $\mathrm{x}$-degree of freedom $(\mathrm{Ux}=0)$. Here it has been assumed that the mid plane deformation along $\mathrm{x}$-direction is zero. The Figure 5.17 showing the internal pressure and the boundary condition applied on the GFRP cylinder. An internal pressure of 1.2 MPa has been applied.

\subsubsection{Results and Discussions}

The stress and deformation pattern is not systematic because of the anisotropic behavior of the material used.
Maximum Von-Mises stress
$=65.00 \mathrm{MPa}$
Maximum longitudinal deformation
$=0.161 \mathrm{~mm}$
Weight of the cylinder$$
=3.02 \mathrm{~kg}
$$

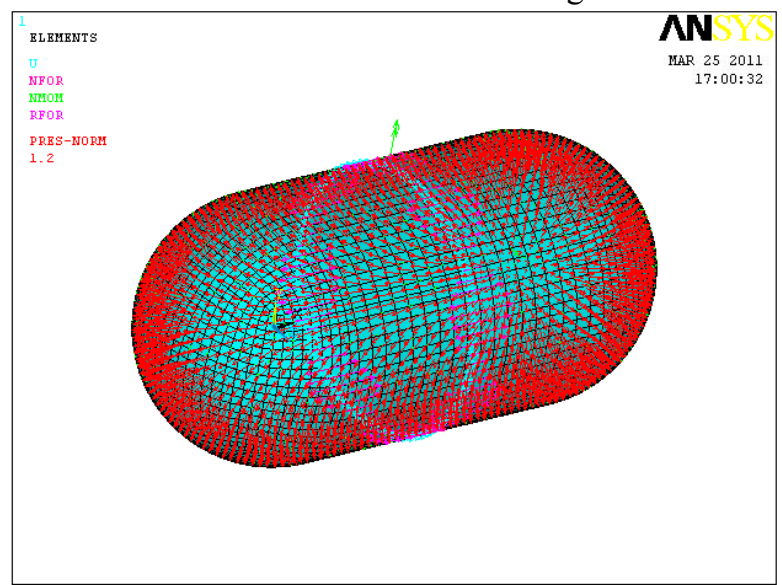

Fig 3.1 Internal pressure applied on GFRP cylinder

Note: Here cylinder has been modeled along $x$-direction, because the fiber orientations in case of FRP cannot be given if it is modeled along z-direction; whereas if we don't model along z-direction, we will not be able to visualize the result (such as hoop stress and deformations) in polar co-ordinate in well fashion. But in any coordinate system von-mises stress and resultant deformation result (which are of prime concern) will remain same. 


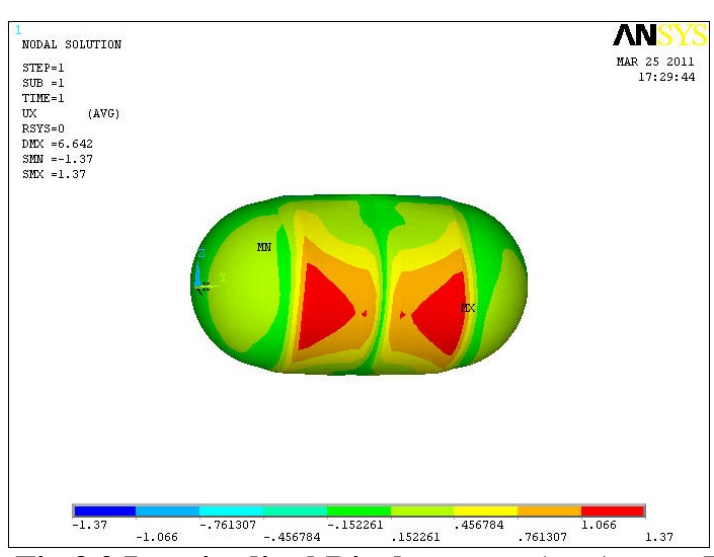

Fig 3.2 Longitudinal Displacement (mm) plot for GFRP cylinder

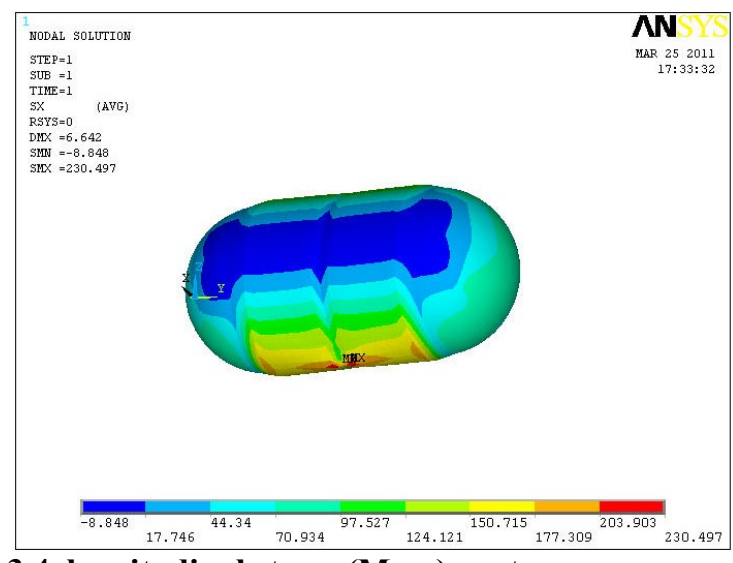

Fig 3.4 longitudinal stress (M pa) contour plot for GFRP cylinder

The Fig 3.2 is the figure shows the max Longitudinal Displacement is 0.61 for GFRP cylinder .

The figure 3.4 is the figure shows the Longitudinal stress is $44.36 \mathrm{M}$ pa for GFRP cylinder .

The stress and deformation pattern is not systematic because of the orthotropic behavior of the material used.

The figure 3.5 is the figure shows the Vonmises stress is $65.00 \mathrm{M} \mathrm{Pa}$ for GFRP cylinder. so, the maximum stress occurring is within the limits and the design is safe.

The figure 3.6 and 3.7 are the figures showing the Interlaminar SXZ shear stress and Interlaminar SYZ shear stress for GFRP cylinder. These stresses are drawn for the middle layer.

The Maximum Interlaminar SXZ shear stress $=0.428$

The Maximum Interlaminar SYZ shear stress $=0.835$

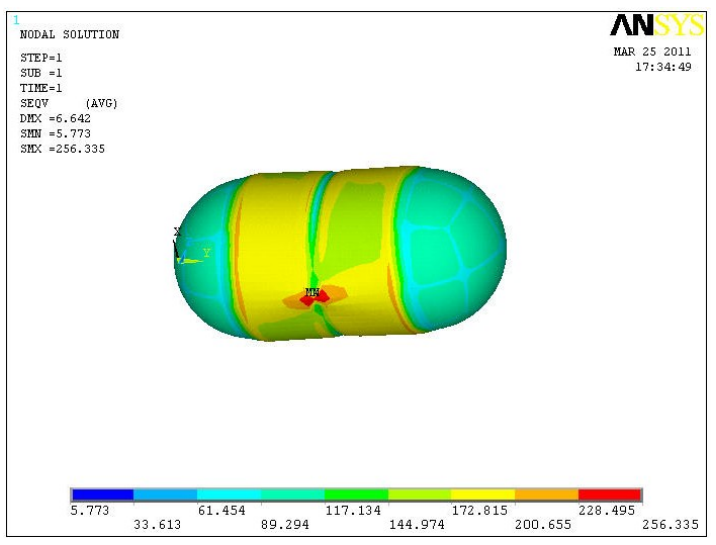

Fig 3.5 Von-mises stress (MPa) contour for GFRP cylinder

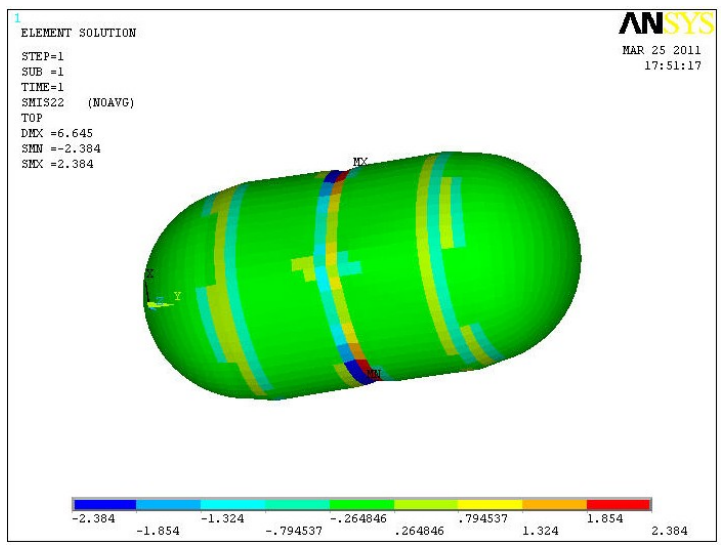

Fig 3.7: Interlaminar SYZ shear stress (M Pa) for GFRP cylinder

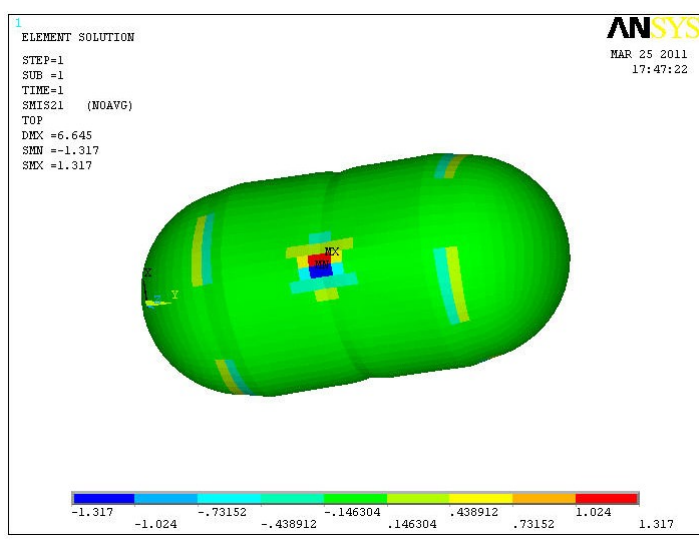

Fig 3.6: Interlaminar SXZ shear stress (MPa) for GFRP cylinder

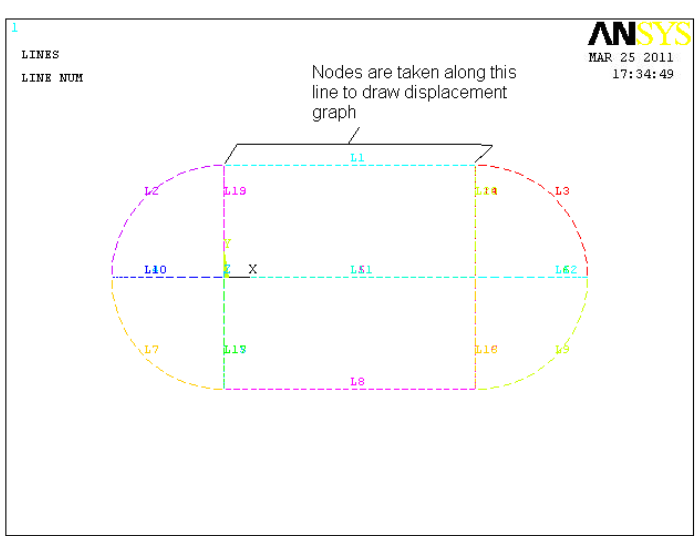

Fig 3.8: Nodes selected along the axis 
The figure 3.8 shows the nodes which are selected to draw the Longitudinal Displacement variation graph (fig 3.9) and the Vonmises Stress variation graph(fig 3.10) for GFRP Cylinder.

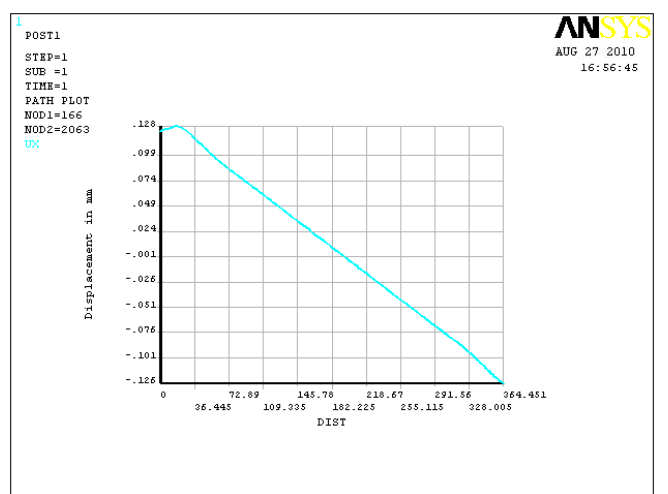

Fig 3.9: Graph showing the variation of Displacement

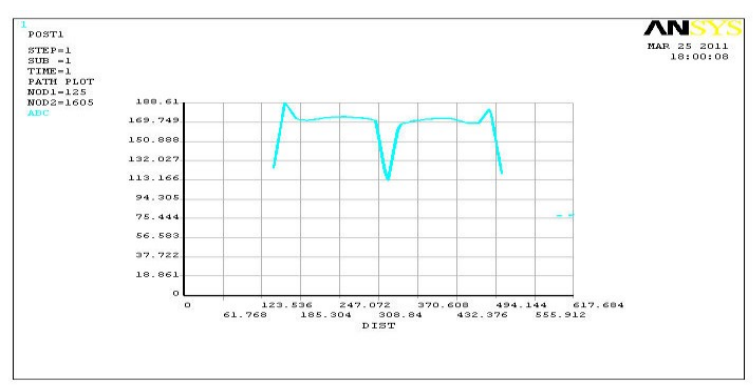

Fig 3.9 Graph showing the variation of Displacement

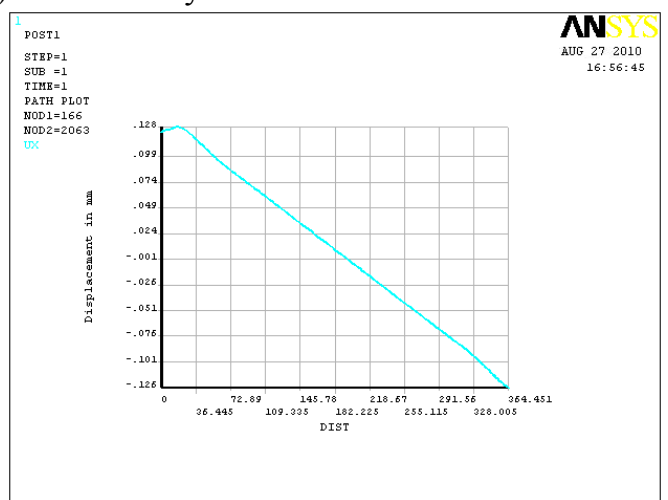

Fig 3.10 : Graph showing the varaiation of Vonmises Stress

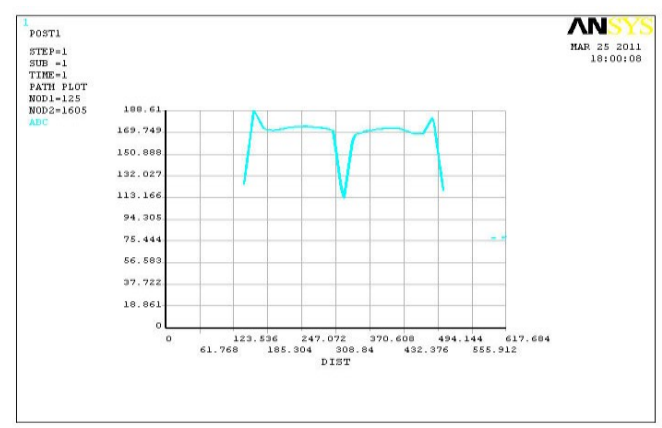

Fig 3.10 : Graph showing the varaiation of Vonmises Stress

Table 3.11 : Comparisons of GFRP and STEEL

\begin{tabular}{|l|l|l|}
\hline CRITERIA & GFRP & STEEL \\
\hline Maximum Vonmises Stress in M Pa & 65 & 68.81 \\
\hline Maximum Longitudinal Stress in M Pa & 44.36 & 43.48 \\
\hline Maximum longitudinal deformation in mm & 0.161 & 0.033 \\
\hline
\end{tabular}

\section{Conclusions}

Based on the analysis of LPG cylinders made of different materials like steel, GFRP ,following conclusions have emerged out from the present investigations:

$\diamond \quad$ The weight of LPG cylinder can be saved enormously by using FRP composites and the stress values are also well within the limit of capability of materials. This gives a clear justification for it's use in household applications.

$\diamond \quad$ Weight of the steel cylinder

$\diamond \quad$ Weight of the GFRP cylinder

$\diamond \quad$ Weight saving

$$
\begin{aligned}
& =13.31 \mathrm{~kg} \text { (without end frames) } \\
& =3.02 \mathrm{~kg} \text { (without end frames) } \\
& =10.29 \mathrm{~kg}
\end{aligned}
$$

\section{References}

[1] Jones, R. M; Mechanics of Composite Materials; Mc Graw Hill Book Co.; 1975.

[2] Mallick, P. K; Fiber Reinforced Composites ; 1997

[3] Agarwal, B. D and Brootman, L. J; Analysis and performance of Fiber Reinforced Composites; Wiley publishers; $2^{\text {nd }}$ Edition; 1990.

[4] Peters, S.T; "Handbook of Composites"; Chapman and Hall London; $2^{\text {nd }}$ Edition; 1998.

[5] Geoff Eckold; "Design and Manufacture of Composite Structures"; Jaico publishing House; 1995.

[6] Vasiliev, V. V and Morozov, E. V; Mechanics and Analysis of Composite Materials; Elsevier Science; 2001.

[7] Kumar, S. and Pradhan, B; Finite Element Analysis of Low-Velocity Impact Damage in Composite Laminates; Journal of Reinforced Plastics and Composites; Vol.19; No. 04/2000.

[8] Jha, S. K and Kumar, S; Finite Element Analysis of Deformations, Stresses and Damages in FRP Composite Laminates Subjected to Uniformly Distributed Loadings; National Conference on Light Metals and Composites for Strategic and Social needs; RRL Trivandrum; October 2002.

[9] Jha, S. K; M. Tech. Thesis on 3-D FE Analysis of FRP Composite Beams and Plates; Mechanical Engineering Department, NIT Jamshedpur; April 2002. 